\title{
A Review of the Exclusion Technique as a Mode of Surgical Repair in the Treatment of Aortoiliac Aneurysms with Spontaneous Arteriovenous Fistulas
}

\author{
H. Tarik Kiziltan, MD \\ Department of Cardiovascular Surgery, Özel Adana Hastanesi, Adana, Turkey
}

\section{ABSTRACT}

Patients with aortoiliac aneurysms with arteriovenous fistulas are difficult to treat. The traditional mode of surgical repair using aneurysmal excision, fistula closure, and graft inclusion has been associated with high perioperative mortality. As an alternative, the exclusion technique also has been utilized. Over the years, the popularity and success rate of endovascular techniques have increased in the treatment of these patients, yet a technical failure during an endovascular repair always makes surgical repair inevitable. This paper aims to review the outcomes of aneurysmal exclusion as a modality of surgical repair in the treatment of patients with aortic and/ or iliac aneurysms with arteriovenous fistulas. The literature in English was researched utilizing the MEDLINE database. Articles reporting on surgical exclusion of abdominal arterial aneurysms with arteriovenous fistulas were included. Overall, four cases in three patients and our unpublished experience in a fifth case were evaluated. There were two aortoiliac, one aortic, one secondary iliac, and one pure iliac artery aneurysm, all with fistulas into the venous system. All patients recovered well following the exclusion operations. There were no operative or 30-day mortalities. One patient had inferior vena cava obstruction. Another patient developed a secondary iliac artery aneurysm with iliac vein fistula two years postoperatively, due to an internal iliac artery, which was not ligated during the first operation. Reported data indicates that for patients who have aortoiliac aneurysms with arteriovenous fistulas, the exclusion technique is a viable surgical alternative either as a first-line choice or when other strategies are technically not feasible.

\section{INTRODUCTION}

An arteriovenous fistula complicating an aneurysm that originated from the abdominal aorta and/or iliac arteries is a serious complication which invariably leads to advanced heart failure and death in untreated cases [Boffi 1955]. Reportedly, it is present in 2 percent to 4 percent of ruptured abdominal aortic aneurysms (AAA), and mortality associated with open surgery ranges between 30 percent and 50 percent in older

Received November 21, 2017; received in revised form May 31, 2018 accepted June 4, 2018.

Correspondence: H. Tarlk Kizlltan, MD, Hasan Kalyoncu University, Lecturer in Vocational School, Gaziantep, Turkey (e-mail: btkiziltan@yahoo.com). series [Gilling-Smith 1991]. Consequently, the traditional surgical operative risk based on aneurysmal excision, fistula closure and graft inclusion remained high for decades, with a mortality rate as high as 50 percent [Gilling-Smith 1991; Maeda 2007]. As an alternative, the exclusion technique originally developed for infra-renal aortic aneurysms [Corson 1987] - which includes division of the aorta with suture closure of the proximal and distal aspects of the aneurysm, and bypass of the excluded segment has also been utilized in the context of aortoiliac aneurysms with aortocaval fistula when fistula itself could not be closed during surgery [Woolley 1995; Batt 1996; Kondo 2011]. In recent years, evolving endovascular techniques have been utilized in this clinical entity with no perioperative mortality and a technical success rate of 96 percent [Antoniou 2009]. Intuitively, a lower operative mortality rate following endovascular repair can be attributed to the diminished risk of air embolism, stabler procedural hemodynamy resulting in fewer postoperative complications, avoidance of general anesthesia, reduced blood loss, and reduced

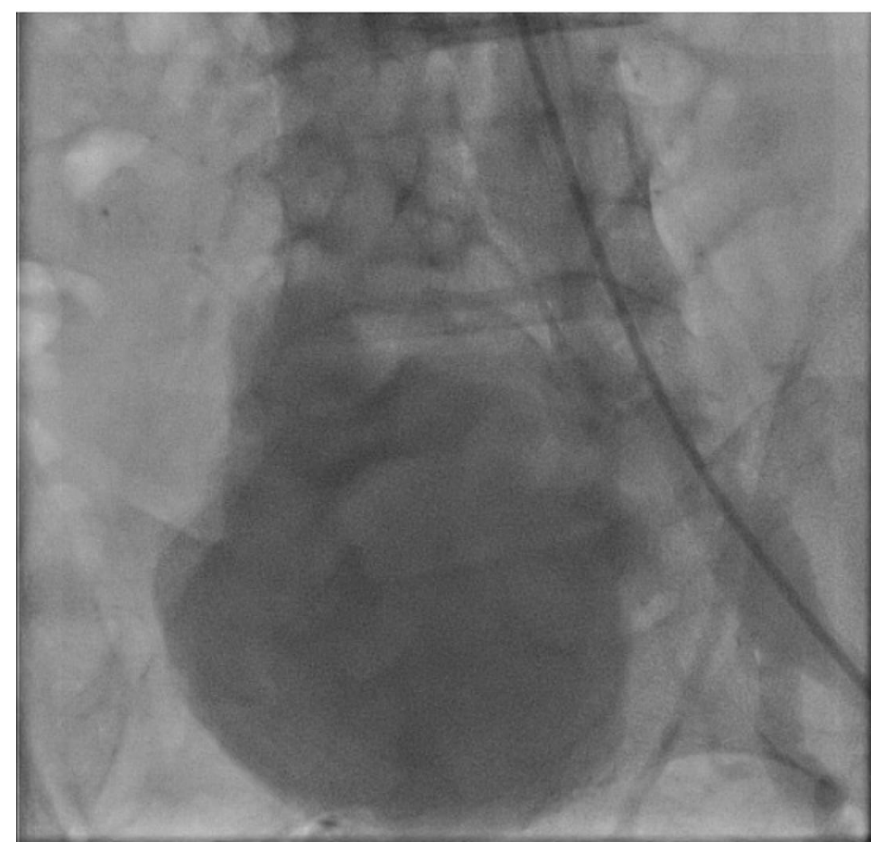

Figure 1. An aortography showing the right common iliac artery aneurysm and fistula into the inferior vena cava. No filling in the distal arterial segments was visualized. Note the irregular contour of the aneurysm wall, which is an indication of thrombi. 


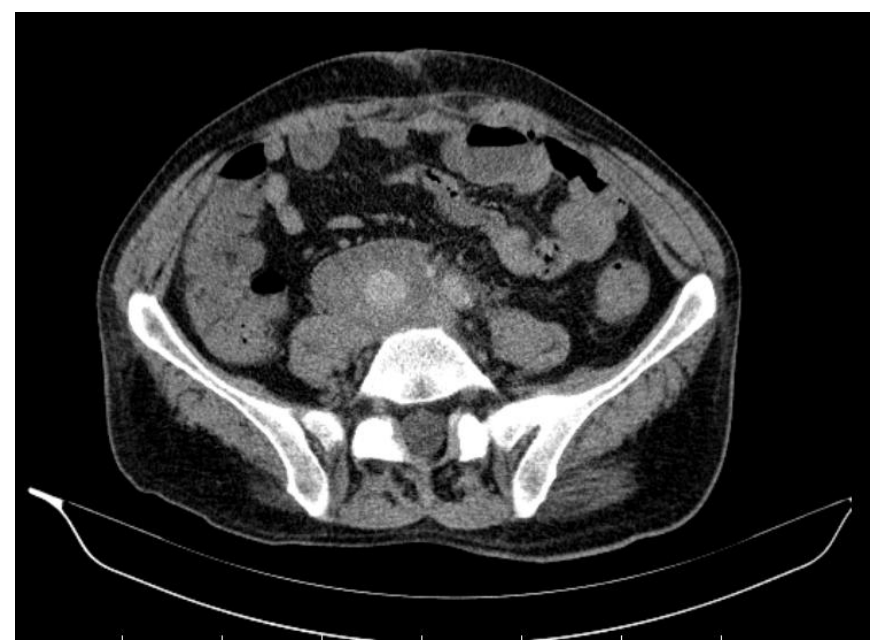

Figure 2. CT angiography demonstrating an endoleak inside the aneurysm two months postoperatively.

risks associated with less blood transfusion. Yet, there is a chance that the real mortality and technical success rates following endovascular repair are not as favorable due to unreported cases [Bernstein 2013]. Furthermore, in the context of aortoiliac aneurysms with spontaneous arteriovenous fistulas, endovascular repair itself is not without problems as it is associated with 42 percent of post-procedural complications, including endoleak, graft thrombosis, graft stenosis, persistent fistula, stent prolapse into the IVC, and persistent aortorenal fistula [Antoniou 2009]. It may also induce inferior vena cava thrombosis [Bernstein 2013]. Clearly, a failure in endovascular repair would also necessitate a surgical approach.

This paper aims to review the outcomes of aneurysmal exclusion as a modality of surgical repair in the treatment of patients who have aortic and/or iliac aneurysms with arteriovenous fistulas.

\section{MATERIALS AND METHODS}

Literature was searched utilizing the MEDLINE database to find all cases of aortic and/or iliac artery aneurysms with spontaneous arteriovenous fistulas treated by surgical exclusion. The key words were aneurysm, arteriovenous, and exclusion. Our search turned up 101 reports spanning from November 1979 to July 2017. A small number of articles in languages other than English were excluded. Of these, four cases reported in three patients were found to be relevant to our research. After adding our unpublished experience, which was performed following a failed endovascular repair, a total of five cases were evaluated.

In addition, our search identified endovascular repair in six patients, and traditional excision and graft inclusion surgery in one patient with the same diagnosis. For the last 15 years, the number of patients undergoing endovascular repair, exclusion surgery, and traditional surgery were six, two, and one, respectively.

Our case includes a 57-year-old male who had $11 \mathrm{~cm}$ right iliac artery aneurysm with an arteriovenous fistula (Figure 1).

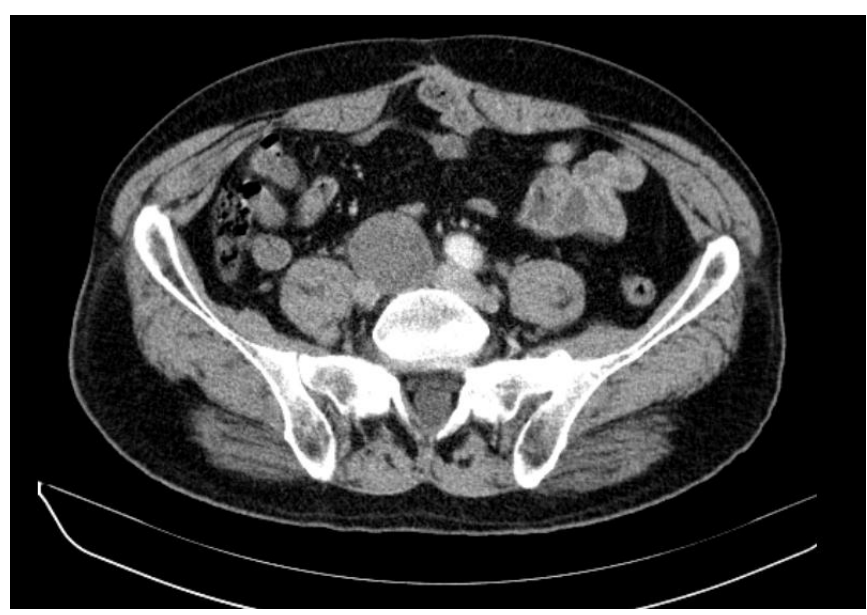

Figure 3. CT angiography with no endoleak one year postoperatively.

An endovascular repair attempt failed because we could not pass the guidewire across the right iliac artery in either an antegrade or a retrograde manner. We decided on an exclusion repair. The main reason we chose the exclusion technique in our patient was to avoid the blood loss and the high hospital mortality associated with the traditional technique. In the operation, we utilized an aortic occluder, which was inserted from the left femoral artery in the angiography room to facilitate dissection around the immediate perimeter of the aneurysm. Extreme care was taken during the dissection to ensure minimal manipulation of the aneurysm itself so as to avoid aneurysmal rupture, and the inferior vena cava obstruction and/or pulmonary embolism caused by dislodged thrombi from the aneurysmal sac. The patient was successfully treated using exclusion surgery, which included ligations of the proximal parts of right common, external and internal iliac arteries, and a left to right femorofemoral bypass using an $8 \mathrm{~mm}$ PTFE graft. A CT angiography on the second postoperative month showed that the iliac artery aneurysm was thrombosed to a large extent, yet there was a contrast leak mimicking a Type II endoleak (Figure 2) at the center of the aneurysm. A conservative approach was chosen [Steinmetz 2004], and the leak disappeared one year postoperatively (Figure 3). He is doing well three years following his surgery.

\section{RESULTS}

All four patients were males, ranging in age from 55 years to 77 years. There were two aortoiliac, one aortic, one secondary iliac, and one pure iliac artery aneurysms with arteriovenous fistulas (Table 1). All fistulas were caused by spontaneous rupture of aneurysmatic wall into the venous system. One patient had venous hypertension due to an IVC clip that was applied during the previous exclusion surgery. Three of the five cases were operated on an emergency or urgency basis, and in two patients the decision for aneurysmal exclusion was made in the operating room because of an unsuitable anatomy for direct fistula repair. In one case (20 percent) diagnosis of arteriovenous fistula was made during the operation. Fistulas 
Patients in the Literature Who Received Exclusion and Bypass For Their Aortic and/or lliac Artery Aneurysm with Arteriovenous Fistula

\begin{tabular}{|c|c|c|c|c|c|c|}
\hline Woolley & 1993 & 1 & $\begin{array}{l}77 \text { YO, M, Back pain, } \\
\text { LE edema, }\end{array}$ & $\begin{array}{l}\text { InfrarenalAAA, fistula } \\
\text { into IVC }\end{array}$ & $\begin{array}{l}\text { LA oversewn; Aortic division, com- } \\
\text { mon IA ligation and ABF bypass }\end{array}$ & $\begin{array}{l}\text { Recovery; IVC thromb. } \\
2 \text { mo. later, did well } 2 \\
\text { yrs. PO; }\end{array}$ \\
\hline Batt & 1996 & 1 & $\begin{array}{l}73 \text { YO, M abdominal } \\
\text { pain, pelvic mass }\end{array}$ & $\begin{array}{c}\text { Primary: AAA fistula } \\
\text { into IVC, 5-cm right IA } \\
\text { aneurysm, }\end{array}$ & $\begin{array}{l}\text { Primary: endoaneurysmal fistula and } \\
\text { iliac orifices closure; IA ligation; IVC } \\
\text { clip; ABF bypass; Second Operation: } \\
\text { fistula closure; internal IA ligation }\end{array}$ & $\begin{array}{c}\text { Recovery; } 3 \text { yrs. PO, } \\
\text { moderate edema in } \\
\text { lower legs due to IVC } \\
\text { clip }\end{array}$ \\
\hline Kondo & 2010 & 1 & $\begin{array}{l}55 \text { YO; M; anuria, } \\
\text { abdominal pain, right } \\
\text { LE pain }\end{array}$ & $\begin{array}{l}\text { Secondary: common IA } \\
\text { aneurysm fistula into } \\
\text { common IV }\end{array}$ & $\begin{array}{l}\text { LA oversewn; aneurysmal sac } \\
\text { oversewn;aorto iliac bypass }\end{array}$ & $\begin{array}{l}\text { Recovery; did well } 1 \\
\text { mo. PO }\end{array}$ \\
\hline Personal Experience & 2014 & 1 & $\begin{array}{l}57 \text { YO; M; Bilateral LE } \\
\text { edema, right LE isch- } \\
\text { emic changes, RHF }\end{array}$ & $\begin{array}{l}\text { Infrarenal AAA; bilateral } \\
\text { common IA aneurysm, } \\
\text { right common IA fistula } \\
\text { into right IV }\end{array}$ & $\begin{array}{c}\text { Ligations of proximal parts of com- } \\
\text { mon, external, internal IA, and FF } \\
\text { bypass }\end{array}$ & $\begin{array}{l}\text { Recovery, did well } 3 \\
\text { yrs. PO }\end{array}$ \\
\hline
\end{tabular}

AAA: abdominal aortic aneurysm; ABF: aorto-bifemoral; FF: femorofemoral; IA: iliac artery; IVC: inferior vena cava; IV: iliac vein; LA: lumbar arteries; LE: lower extremity; M: male; PO: postoperatively; RHF: right heart failure; thromb: thrombosis; YO: year-old

were aortocaval in two (40 percent) and ilioiliac in three (60 percent) cases. In all patients, arterial segments proximal and distal to the aneurysmal sac were closed and bypasses were successfully performed. Bypasses utilized during exclusion procedures were aortofemoral or aorto-iliac in four (80 percent) cases and femorofemoral in one (20 percent) case. The patient who developed a secondary iliac aneurysm underwent a successful repair, during which the fistula - having been already excluded - was closed and right internal iliac artery was ligated. Also, a failed common iliac artery suture was found inside the false aneurysm in the operation. No operative or 30-day mortality was seen. Hospital stay ranged from nine to 53 days. One patient developed an IVC obstruction early postoperatively, which was successfully managed medically. Another patient experienced a secondary iliac artery aneurysm with iliac vein fistula and a false aneurysm two years postoperatively. At the time of their reports, all patients were doing well, ranging one month to three years postoperatively.

\section{DISCUSSION}

Historically, an aortoiliac aneurysm with a spontaneous arteriovenous fistula has been a considerable challenge for medical professionals in terms of diagnosis, operative difficulties, and management of perioperative problems [Boffi 1955; Gilling-Smith 1991; Maeda 2007]. The clinical presentation is characterized by a distinct syndrome [Nennhaus 1968] that includes a painful palpable abdominal mass, an abdominal loud machinery murmur, high output cardiac failure with elevated venous pressure, and pulmonary edema. Signs of reduced systemic circulation such as confusion, lethargy, and renal failure also may accompany the clinical constellation [Gilling-Smith 1991].
The first exclusion technique for an AAA was described by Corson [Corson 1987], and the procedure later was proven to be an efficient technique with reduced blood loss and blood transfusion [Darling 1992; Shah 1991]. Utilization of the exclusion technique for an AAA and a coexisting arteriovenous fistula was reported by Woolley for the first time in a patient where primary repair of the fistula was not possible [Woolley 1995].

The exclusion technique itself relies on the mechanism in which reduced blood flow inside the aortic aneurysm would trigger thrombosis. Therefore, the whole aneurysmal sac would thrombose, closing the fistula without thrombi migrating into the cava. In this technique, since the fistula has been left untouched there is a possibility that a dislodged thrombus would cause inferior vena cava obstruction or pulmonary embolism. In this series, one patient experienced IVC obstruction postoperatively, and the authors attributed this complication to the dislodged aneurysmal thrombi [Woolley, 1995]. Pulmonary embolism following exclusion operations is yet to be reported. Theoretically, these two major risks also apply to endovascular repair [Bernstein 2013] during which arterial continuity is restored while fistula and aneurysmal thrombi are left untouched.

The case that Batt reported was a secondary rupture of an iliac artery aneurysm into the iliac vein in a patient who had undergone an exclusion and bypass operation for an aortoiliac aneurysm with IVC fistula two years previously [Batt 1996]. The patient had also received closure of the common iliac arteries origins, IVC closure with a clip and ligation of the $5 \mathrm{~cm}$ iliac artery aneurysm during the first operation. The deep femoral artery and internal iliac artery were found to be the route that contrast material entered the aneurysm. In the second operation, authors successfully closed the $20 \mathrm{~mm}$ 
fistula and ligated internal iliac artery. The patient recovered and authors concluded that exclusion of aortoiliac aneurysms was an unreliable technique and inclusion bypass was preferable. We believe this conclusion is controversial because the surgical technique they utilized lacked the ligation of right internal iliac artery during the first operation.

We believe patients should be monitored closely following a surgical exclusion in regard to aneurysmal thrombosis. Clearly, in case of an endoleak associated with a major collateral artery feeding the aneurysm, future enlargement and possible complications such as aneurysmal rupture and/ or dissection may ensue. In this regard, during an exclusion repair addressing an aortoiliac aneurysm with an arteriovenous fistula, major sources of arterial circulation opening to the aneurysmal sac - lumbar arteries in an AAA and internal iliac artery when its orifice included in the iliac artery aneurysm - should be deliberately eliminated by closure or fine ligation.

We utilized a femorofemoral crossover bypass instead of distal aorta to external iliac artery bypass because of the huge aneurysmal size, which we believed would make bypass graft positioning complicated. Also, graft positioning would require unnecessary manipulation of the aneurysmal sac which would dislodge aneurysmal thrombi. In addition, any graft positioning overlaying the aneurysm would expose the graft to possible kinking with shrinking of the aneurysm in the future because of reduced blood pressure and thrombus formation inside the aneurysmal sac overtime.

Even though this study is neither intended nor designed to study patients undergoing endovascular repair, it is clear that endovascular repair is more attractive for the clinicians, and surgical techniques are underrated for the treatment of this group of patients.

In our experience, the aortic occluder was an excellent tool to provide a tension-free arterial anatomy adjacent to the aneurysm, thus avoiding complications during surgical dissection.

Our research shows that exclusion technique is a viable surgical option in the treatment of patients who have aortoiliac aneurysms with arteriovenous fistulas especially when high risks are anticipated with the other strategies or a procedural failure occurs during an endovascular repair.

\section{REFERENCES}

Antoniou GA, Koutsias S, Karathanos C, et al. 2009. Endovascular stentgraft repair of major abdominal arteriovenous fistula: a systematic review. J Endovasc Ther 16:514-23.

Batt M, Rogopoulos A, Bariseel H, et al. 1996. Secondary rupture of an iliac artery aneurysm after exclusion-bypass. Ann Vasc Surg 10:296-9.

Bernstein J, Jimenez JC. 2013. Inferior vena cava thrombosis following endovascular repair of acute aortocaval fistula: a word of caution. Vasc Endovascular Surg 47:467-9.

Boffi L. 1955. Rottura di aneurisma dell' aorta abdominal nella vena cava inferiore: rassegnadellaletteratura e studio clinico. Chir Patol Sper 3:73-94.

Colley AL, Annon WT. 1965. Aortic vena caval fistula from ruptured aortic aneurysm. JAMA 194:1137-8.

Corson JD, Leather PR, Shah DM, et al. 1987. Extraperitoneal aortofemoral bypass with exclusion of the intact infrarenal aortic aneurysm. J Cardiovasc Surg 28:274-6.

Darling RC, Shah DM, McClellan WR, et al. 1992. Decreased morbidity associated with retroperitoneal exclusion treatment for abdominal aortic aneurysm. J Cardiovasc Surg 33:65-9.

Gilling-Smith GL, Mansfield AO. 1991. Spontaneous abdominal arteriovenous fistulae: report of eight cases and review of the literature. $\mathrm{Br} \mathrm{J}$ Surg 78:421-426.

Kondo N, Takahashi K, Takeuchi S, et al. 2011. Surgical repair of arteriovenous fistula associated with infrarenal aorto-iliac aneurysm: Report of two contrasting cases. Ann Vasc Dis. 4:150-3.

Maeda H, Umezawa H, Goshima M, et al. 2007. Surgery for ruptured abdominal aortic aneurysm with an aortocaval and iliac vein fistula. Surg Today 37:445-6.

Magee HR, Mellick SA. 1977. Aortocaval fistula as a complication of leaking aortic aneurysm. Br J Surg 64:239-41.

Nennhaus HP, Javid H. 1968. The distinct syndrome of spontaneous abdominal aortic-caval fistula. Am J Med 44:464-73.

Shah DM, Chang BB, Paty SK, et al. 1991. Treatment of abdominal aortic aneurysm by exclusion and bypass: an analysis of outcome. J Vasc Surg 13:15-22.

Steinmetz E, Rubin BG, Sanchez LA, et al. 2004. Type II endoleak after endovascular abdominal aortic aneurysm repair: a conservative approach with selective intervention is safe and cost-effective. J Vasc Surg 39:306-13.

Woolley DS, Spence RK. 1995. Aortocaval fistula treated by aortic exclusion. J Vasc Surg 22:639-42. 